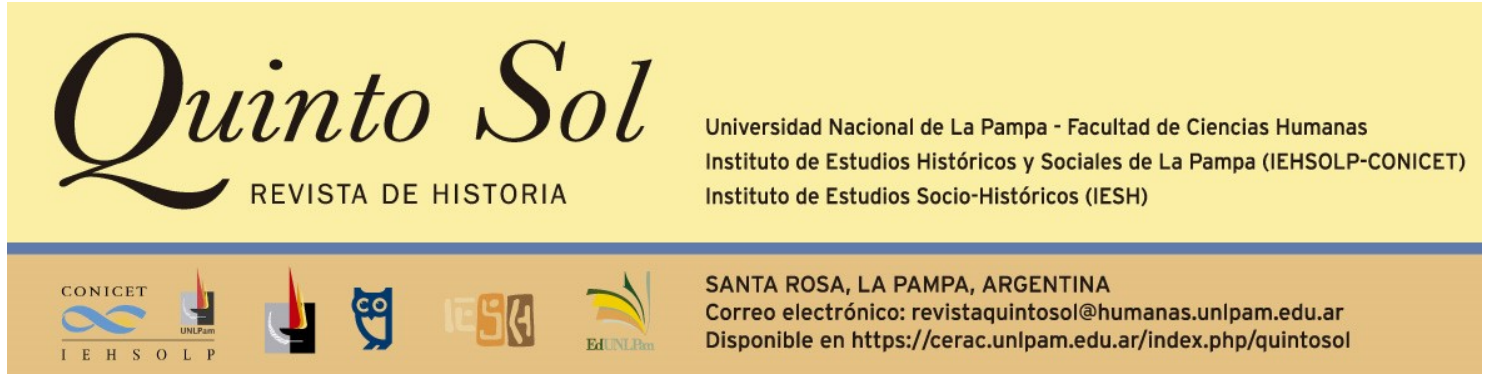

Quinto Sol, vol. 24, n² 2, mayo-agosto 2020, ISSN 1851-2879, pp. 1-4

DOI: http://dx.doi.org/10.19137/qs.v24i2.4118

Esta obra se publica bajo licencia Creative Commons 4.0 Internacional. (Atribución-No ComercialCompartir Igual)

\title{
Paula Bruno. Martín García Mérou. Vida intelectual y diplomática en las Américas. Bernal: Universidad Nacional de Quilmes, 2018, 211 páginas.
}

\author{
Alicia San Martín Molina \\ Universidad Complutense de Madrid \\ España \\ Correo electrónico: aliciasanmartin@ucm.es
}

En 1878 el argentino Martín García Mérou obtuvo un reconocimiento en un concurso literario del colegio que le valió el apoyo y la protección, entre otros, de los intelectuales Miguel Cané y Manuel Estrada. Con tan sólo diecinueve años fue nombrado oficial secretario de Cané en Venezuela y Colombia abriéndose así una nueva etapa en su vida de donde surgió la obra Impresiones (1884). Desde entonces, y hasta su muerte en 1905, García Mérou vivirá la mayor parte de su vida fuera de Argentina para representarla y lo hará en un contexto muy específico, el cambio del siglo XIX al XX. Aprovechará sus estancias en los distintos países tanto para recopilar materiales como para escribir sus experiencias y análisis que le permitirán a su vez proponer sus propias reflexiones ante sucesos internacionales. Estas reflexiones propias, así como su distanciamiento de los temas predominantes de la época, hacen que el perfil de García Mérou deba ser estudiado desde otra perspectiva distinta a la de 
varios de sus contemporáneos que también realizaron labores en el exterior. Precisamente, Paula Bruno con esta obra nos presenta a un intelectual-diplomático, ya que en García Mérou la vida intelectual y diplomática se unen, y nos invita a volver a pensarlo y leerlo de manera integral a través de sus textos.

Este interés de Bruno por las "vidas intelectuales", por la aproximación biográfica para estudiar una época, no es reciente. Fue promotora de la Red de Estudios Biográficos de América Latina -REBAL-y desde hace años esta historiadora ha publicado varias obras que se enfocan en esa cuestión, distanciándose del modelo de biografía intelectual e inscribiéndose en la historia social de los intelectuales. Para ello, combina en sus trabajos rasgos y circunstancias biográficas con ideas y tramas sociales culturales que le permiten reconstruir los distintos perfiles. Caben mencionar sus libros Paul Groussac. Un estratega intelectual (2005) o Pioneros culturales de la Argentina. Biografías de una época, 1860-1910 (2011). En este último propone un acercamiento a la vida cultural del país de la segunda mitad del siglo XIX e inicios del XX a través de distintas biografías, entre ellas las de Paul Groussac, José Manuel Estrada o Eduardo Wilde, hombres a los que también hará referencia en la obra reseñada y que muestran junto con García Mérou las singularidades de la vida cultural de la época. Por ejemplo, Wilde y García Mérou son dos casos de la conformación de nuevas interpretaciones optimistas acerca del ascenso de Estados Unidos desarrolladas a partir de una experiencia diplomática con el propio país.

El ensayo está compuesto por cuatro puntos a modo de estudio introductorio con sus respectivas consideraciones finales y bibliografía- y una antología compuesta por dieciocho textos. Esta estructura logra que la autora pueda proponer al lector un estudio del perfil completo de García Mérou y es importante señalar que focaliza su atención en los aspectos públicos del personaje y lo sitúa en un lugar destacado en el panorama intelectual de fin de siglo. La disposición de los capítulos responde a ejes temáticos - para evitar una segmentación de su itinerario intelectual- donde da cuenta de la vida intelectual del personaje, de lo que escribió, de las sociabilidades intelectuales en las que participó en Argentina, de su ejercicio como diplomático. Así pues, la autora tiene en cuenta el contexto sociocultural y a partir de ahí explora las sociabilidades, las dinámicas culturales de las naciones latinoamericanas, el mundo editorial, los hombres de cultura, las inserciones institucionales, la participación de García Mérou en distintas publicaciones y su intervención pública. Para ello usará diferentes fuentes documentales, periódicos, artículos, ensayos interpretativos y testimonios.

En el primero de los puntos, "Trayectorias y recuperaciones", Bruno nos ofrece datos biográficos que permiten situar al personaje cronológicamente y dan cuenta de su intensa vida al servicio de la nación como diplomático. En 1886, Julio A. Roca designó a García Mérou ministro residente en Paraguay, en 1891 es nombrado ministro plenipotenciario y con este cargo residió en Perú, Brasil y Estados Unidos. Es precisamente en este punto donde la autora traza los ejes en torno a los que van a girar los siguientes capítulos, que permitirán rastrear el itinerario intelectual de García Mérou y ver que su producción tuvo un carácter diferencial. El capítulo dos, "Cartografías y constelaciones latinoamericanas", se centra en el primero de los ejes que está relacionado con los otros dos. A través de él cuenta las miradas y estudios de las dinámicas culturales de las naciones latinoamericanas. Estas geografías precisamente dieron a García Mérou una nueva oportunidad para pensar el continente 
americano. Aquí Bruno da especial atención a Brasil y establece una clara diferencia entre otros intelectuales y el personaje del que se ocupa. Mientras que muchos de los intelectuales del siglo XIX, tras sus visitas a Brasil, usaban los tópicos del tropicalismo para describir lo observado, García Mérou, a través de su obra Brasil intelectual (1900), pensará de manera orgánica el país abandonando las tentaciones de los anteriores de evocar vegetación y fauna. Es importante señalar que, a lo largo del trabajo, Bruno deja claro que el perfil de este personaje es distinto al de otros intelectuales a los que la historiografía ha prestado mayor atención. Precisamente, nos está proponiendo en su trabajo ver, o más bien leer, esa diferencia en los propios textos de este autor. El capítulo tres, "Vida intelectual Argentina", aborda el segundo de los ejes y allí Bruno muestra de qué forma García Mérou trazó y periodizó la vida intelectual argentina a través de sus estudios sobre los padres fundadores y de algunos intelectuales mayores que él. Su labor como diplomático hace que tenga que estar fuera de Argentina observando su país desde la distancia, pero es eso, según la autora, lo que le permite cartografiar y periodizar esa vida cultural. De hecho, sus opiniones sobre el noventa están vertidas desde fuera del país. De este capítulo cabe destacar la puntualización que hace Bruno acerca de las lecturas de la obra más reeditada de García Mérou: Recuerdos literarios (1891). En él ofrece su interpretación de por qué cree que hay elementos que han pasado inadvertidos en las lecturas e investigaciones vigentes. En el último de los capítulos, "Conocer y describir las Américas", expone el tercero de los ejes en el que pone de relieve los análisis de García Mérou sobre la reconfiguración del escenario geopolítico americano, prestando especial atención a qué lugar ocupaba Brasil y Estados Unidos en él y qué papel podía tener Argentina. Bruno señala la I Conferencia Panamericana celebrada en Washington como el origen de las reflexiones de García Mérou sobre Brasil y Estados Unidos en el escenario continental. Destaca como este diplomático era optimista acerca del ascenso de Estados Unidos que podía ser un ejemplo cultural, político y económico. Aunque quizás uno de los puntos más interesantes de este apartado es la detección que hace Bruno de dos momentos en el pensamiento de García Mérou. Nos muestra a lo largo de estas páginas que hay un García Mérou "signado por la coyuntura" que envía crónicas al diario La Nación -cuyas columnas eran publicadas como "Noticias Americanas"- y otro García Mérou "más reflexivo" cuyo pensamiento queda reflejado en Historia de la diplomacia americana (1904) y es precisamente aquí donde priman esas miradas optimistas señaladas.

Este estudio preliminar finaliza con unas "consideraciones finales" donde la autora va recogiendo cada una de las ideas planteadas a lo largo de su trabajo y que conducen todas ellas a demostrar que la lectura atenta de las obras de García Mérou plantean una serie de desafíos en el marco de las interpretaciones vigentes. Muestra también la importancia de la figura del diplomático y la diferencia con el que perfila David Viñas al que vincula con el ocio, los tiempos muertos o el aburrimiento. Bruno deja claro, a lo largo del ensayo, pero sobre todo en este punto, que García Mérou no encaja en esa caracterización y su itinerario intelectual fue distinto al de varios de sus contemporáneos, idea esta última también repetida a la largo del trabajo. Respecto al apartado de bibliografía, la autora incluye las fuentes documentales utilizadas y divide la bibliografía en dos secciones. Por un lado, las obras publicadas de Martín García Mérou donde establece un orden cronológico y, por otro, una selección de trabajos sobre él. 
La segunda parte de este ensayo, tal y como mencionábamos anteriormente, está compuesta por una acertada antología. En ella la autora ha seleccionado dieciocho textos -capítulos o fragmentos escritos por García Mérou durante más de veinte añosy especifica que ha usado un criterio temático. En las notas a pie de página el lector encuentra la referencia completa de cada obra para que pueda localizarla, así como su fecha de publicación $y$, en algunos casos, aclaraciones respecto a las mismas. La variedad de los textos, ensayos críticos, memorias, recuerdos de viajes en estadías, historia diplomática, ficción y notas de análisis de coyunturas dan cuenta del gran esfuerzo de Bruno en la propia selección para organizar la producción de García Mérou en los tres ejes que plantea en el libro.

Así pues, este nuevo trabajo de Paula Bruno evidencia la necesidad de leer a Martín García Mérou de manera integral y permite repensar la relación entre tarea intelectual y diplomacia.

\section{Referencias bibliográficas}

1. Bruno, P. (2005). Paul Groussac. Un estratega intelectual. Buenos Aires, Argentina: Fondo de Cultura Económica/Universidad de San Andrés.

2. Bruno, P. (2011). Pioneros culturales de la Argentina. Biografías de una época, 1860-1910. Buenos Aires, Argentina: Siglo XXI.

3. García Mérou, M. (1884). Impresiones. Madrid, España: M. Murillo.

4. García Mérou, M. (1891). Recuerdos literarios. Buenos Aires, Argentina: Félix Lajouane.

5. García Mérou, M. (1900). El Brasil intelectual. Impresiones y notas literarias. Buenos Aires, Argentina: Félix Lajouane.

6. García Mérou, M. (1904). Historia de la diplomacia americana. Política internacional de los Estados Unidos. Tomo primero y segundo. Buenos Aires, Argentina: Félix Lajouane. 